\title{
Osteoarticular infection in intravenous drug abusers: influence of HIV infection and differences with non drug abusers
}

\author{
S Muñoz-Fernández, M A Maciá, L Pantoja, A Cardenal, J M Peña, E Martín Mola, \\ A Balsa, F J Barbado, J J Vázquez, J Gijón Baños
}

\begin{abstract}
Objectives-To determine (a) the influence of HIV in developing osteoarticular infections in intravenous drug abusers (IVDAs) and (b) the differences between the clinical features of osteoarticular infections in IVDAs and a control group of non-IVDAs.

Methods-A comparative study of the clinical features of osteoarticular infections in all HIV positive and HIV negative IVDAs admitted to the departments of rheumatology and internal medicine during a 10 year period was carried out. The joint infections of all IVDAs, irrespective of HIV status, were compared with those of a control group of nonIVDAs lacking risk factors for HIV infection.
\end{abstract}

Results-A total of 482 HIV positive and 85 HIV negative IVDAs was studied, in whom $25(5 \%)$ and six (7\%) osteoarticular infections were found respectively. There were no differences in age, sex, joints affected, and causative agents between these two groups. A comparison of the 31 $(5 \cdot 5 \%)$ osteoarticular infections in all IVDAs with 21 infections in $616(3 \cdot 4 \%)$ non-IVDAs showed significant differences in the mean age $(27.5 v 54)$, the frequency of affection of the axial joints (hip, sacroiliac, and sternocostal joints) $(64 \cdot 5 \%$ $v 16 \cdot 6 \%$ ), and in the incidence of Candida albicans $(19 \% v 0 \%)$.

Conclusions-(1) HIV may not predispose to osteoarticular infections in IVDAs. (2) The hip, sacroiliac, and sternocostal joints (axial joints) were most commonly affected in IVDAs. (3) In Spain, unlike other countries, Gram positive bacteria and $C$ albicans seem to be predominant agents in osteoarticular infections in IVDAs, with a low incidence of Gram negative bacteria.

(Ann Rheum Dis 1993; 52: 570-574)

The human immunodeficiency virus (HIV), one of the main protagonists of the last decade, has a role in all clinical fields. In 1985 psoriasis was first reported in relation to HIV, ${ }^{1}$ and in 1987 Reiter's syndrome was described as a possible HIV associated disease. ${ }^{2}$ Since these initial reports some investigators have studied the incidence and prevalence of rheumatic syndromes in association with HIV infection. A predominance of seronegative spondylarthritis in studies among homosexual men ${ }^{3-5}$ and of osteoarticular infections among intravenous drug abusers (IVDAs) ${ }^{6-10}$ may exist. Furthermore, septic arthritis has been found only rarely when homosexuality is the principal risk factor for HIV infection. ${ }^{3-5}$ This suggests that risk factors for HIV infection may influence the expression of HIV related rheumatic syndromes.

On the other hand, septic arthritis in IVDAs might have different features than in nonIVDAs. The former might have infections of the axial joints more commonly than the latter; this has not been proved.

The objectives of our study were to determine (a) the influence of HIV on the incidence of osteoarticular infections in IVDAs and $(b)$ the differences between osteoarticular infections in IVDAs and non-IVDAs.

\section{Patients and methods}

We included in the study all IVDAs (with or without HIV infection) admitted to the department of internal medicine and rheumatology of our hospital from 1981 to 1990 . Patients with other risks for HIV infection were excluded. In all patients a clinical protocol was completed, which included age, sex, joints affected, causative agent and site of isolation, predisposing factor for osteoarticular infection, HIV status and group of Centers of Disease Control (CDC) classification in positive cases, radiological abnormalities, treatment given, and response achieved. A possible relation between acquired immunodeficiency syndrome (AIDS) and osteoarticular infections was specifically looked for. Diagnosis of an episode of osteoarticular infection was made by a compatible clinical picture of septic arthritis, discitis, or osteomyelitis and isolation of the causative agent in synovial fluid, blood, or tissue biopsy specimen.

Intravenous drug abusers were divided into HIV positive and negative groups. HIV serological tests were performed by an enzyme linked immunosorbent assay (ELISA) and confirmed by western blot. AIDS was diagnosed according to the CDC criteria as previously published. ${ }^{11}$ HIV infected patients were classified by the CDC system. ${ }^{12}$ The presence of osteoarticular infections, age, causative agents, and joints affected were compared in the two groups. 
Table 11986 Centers of Disease Control (CDC) classification system for HIV infection ${ }^{12}$

\begin{tabular}{|c|c|}
\hline $\begin{array}{l}\text { Group I } \\
\text { Group II } \\
\text { Group III }\end{array}$ & $\begin{array}{l}\text { Acute infection } \\
\text { Asymptomatic infection } \\
\text { Persistent generalised lymphadenopathy }\end{array}$ \\
\hline Group IV & \\
\hline Subgroup A & Constitutional disease \\
\hline Subgroup B & Neurological disease \\
\hline Subgroup C & Secondary infectious diseases \\
\hline Category C-1 & $\begin{array}{l}\text { Specified secondary infectious diseases } \\
\text { listed in the CDC surveillance } \\
\text { definition of AIDS }\end{array}$ \\
\hline Category C-2 & $\begin{array}{l}\text { Other specified secondary infectious } \\
\text { diseases }\end{array}$ \\
\hline Subgroup D & Secondary cancers \\
\hline Subgroup & ther condition \\
\hline
\end{tabular}

To investigate a possible relation between osteoarticular infections and a more profound immunological depression we subdivided HIV positive patients with osteoarticular infections in accordance with the CDC classification system (table 1). This distribution was compared with the prevalence of each CDC group in the HIV positive patients without osteoarticular infections.

To determine the differences between osteoarticular infections in IVDAs and nonIVDAs we compared age, predisposing factors for a skeletal infection, causative agents, and affected joints in all IVDAs, irrespective of their HIV status, with a group of non-IVDAs with osteoarticular infections. The non-IVDAs were recruited from all subjects lacking risk factors for HIV infection admitted to the department of rheumatology over five years (1986 to 1991).

Statistical analysis was performed with Fisher's exact test. A difference between the mean age of each group more than 2 or 2.6 times greater than the standard error was considered significant $(p<0.05$ or $p<0.01$ respectively). When the groups were small we compared the mean age using the appropriate correction of the standard error and Student's $t$ values.

\section{Results}

COMPARATIVE STUDY OF IDVAS WITH AND WITHOUT HIV INFECTION

During a 10 year period 567 IVDAs were studied. Of these, 482 (85\%) were HIV seropositive and 85 (15\%) HIV seronegative. Mean age was 27 years in the HIV positive patients (range 17-39 years) and 29 in the HIV

Table 2 Comparative study of HIV positive and HIV negative intravenous drug abusers (IVDAs) and non-IVDAs. Results show number (percentage) of patients

\begin{tabular}{llcl}
\hline & $\begin{array}{l}\text { HIV positive IVDAs } \\
(n=482)\end{array}$ & $\begin{array}{l}\text { HIV negative IVDAs } \\
(n=85)\end{array}$ & $\begin{array}{l}\text { Non-IVDAs } \\
(n=616)\end{array}$ \\
\hline Infections & $25(5)$ & $6(7)$ & $21(3 \cdot 4)$ \\
Mean age (years) & 27 & 29 & 54 \\
Sex (M:F) & $20: 5$ & $5: 1$ & $13: 8$ \\
Joints or bones infected & $7(28)$ & $1(17)$ & $2(10)$ \\
$\quad$ Hip & $4(16)$ & $3(50)$ & $1(5)$ \\
Sacroiliac & $4(16)$ & $1(17)$ & $8(38)$ \\
Sternocostal & $3(12)$ & - & $10(48)$ \\
Knee & $7(28)$ & & \\
Other & & $4(67)$ & $14(67)$ \\
Agents & $13(52)$ & $1(17)$ & - \\
Saureus & $5(20)$ & $1(17)$ & $4(19)$ \\
Calbicans & $1(4)$ & - & $2(10)$ \\
Tuberculosis & - & - & $1(5)$ \\
Pneumococcus & $6(24)$ & & \\
Other & & & \\
\hline
\end{tabular}

negative patients (range $23-37$ years). In the HIV positive group $80 \%$ were men and $20 \%$ women, and the HIV negative group comprised $83 \%$ men and $17 \%$ women.

We found 25 osteoarticular infections $(5 \%)$ in HIV positive patients and six (7\%) in HIV negative patients. In the first group the affected joints were the hip (seven patients $(28 \%)$ ), sacroiliac joint (four (16\%)), sternocostal joint (four $(16 \%))$, knee (three $(12 \%))$, and shoulder and disc L3-4 in one case each. In one patient a polyarticular involvement of elbows and wrists was found, and in another the ankle and shoulder were both affected. Osteomyelitis was present in three patients (wrist, femoral neck, and tibia). In HIV negative patients the affected joints were the sacroiliac joint in three $(50 \%)$ patients and hip, sternocostal joint, and knee in one each. Although sacroiliac joint infection was more common in HIV negative than in HIV positive patients $(50 \% v 16 \%)$, the difference was not significant. Although osteomyelitis was not found in the HIV negative group, statistical analysis was not possible owing to the small number of HIV positive patients with osteomyelitis.

In the 25 HIV positive patients with osteoarticular infections the causative agents were Staphylococcus aureus in 12 (48\%), Candida albicans in five $(20 \%)$, and Mucor, Neisseria gonorrhoeae, Mycobacterium tuberculosis, Staphylococcus epidermidis, Streptococcus viridans, Streptococcus equisimilis, and Streptococcus sanguis in one case each. Additionally, $S$ aureus and Bacteroides melaninogenicus were found in one patient.

In the six HIV negative patients with osteoarticular infections the causative agents were $S$ aureus in four (67\%) and $C$ albicans and $M$ tuberculosis in one case each.

No significant differences in the incidence of infections, age, sex, joints affected, and causative agents were found between HIV positive and negative patients (table 2 ).

Of the $25 \mathrm{HIV}$ positive patients with osteoarticular infections, $11(44 \%)$ were in CDC group II, four (16\%) in group III, four $(16 \%)$ in group IV-C2, and six $(24 \%)$ in group $\mathrm{IV}-\mathrm{Cl}$ and had criteria of AIDS.

\section{COMPARATIVE STUDY OF IVDAS AND NON-}

IVDAs

A group of 616 non-IVDAs with no risk factor for HIV infection were compared with all the IVDAs, irrespective of HIV status. In the former group $21(3.4 \%)$ had osteoarticular infections and in the latter $31(5.5 \%)$. The mean age of the non-IVDAs was 54 years (range 15-78) and of the IVDAs 27.5 years (range 17-39), which was significantly different $(p<0.01)$. Of the 21 non-IVDAs, $13(62 \%)$ were men and eight $(38 \%)$ women, whereas of the 31 IVDAs, $25(81 \%)$ were men and six $(19 \%)$ women.

In 16 of the 21 non-IVDAs with osteoarticular infections a predisposing factor was found. Six had previous skin or wound infections, and rheumatoid arthritis, diabetes 
mellitus, pneumonia, and alcoholism were each present in two patients, one had systemic lupus erythematosus, and another had multiple myeloma. In addition to the soft tissue and skin infections commonly found in IVDAs, six of the 31 with osteoarticular infections $(20 \%)$ had disseminated candidiasis (with the sternocostal joint affected in five patients and the hip in one) and six $(20 \%)$ had infectious endocarditis. Of these, five had tricuspid endocarditis caused by $S$ aureus and one had mitral endocarditis due to $S$ sanguis. (This patient also had osteomyelitis of the tibia.)

The affected joints in the 21 non-IVDAs were knees (eight patients $(38 \%)$ ), intervertebral discs (three (14\%)), wrists (two (10\%)), elbows (two $(10 \%)$, hips (two $(10 \%)$ ), and ankle, sacroiliac joint, and shoulder in one case each. Another patient had septic oligoarthritis of the wrist, shoulder, and ankle. Classifying the affected joints as axial (sternocostal, sacroiliac, intervertebral, and hip joints) or peripheral, we found that the axial joints were more commonly affected in the IVDAs than in the non-IVDAs $(64.5 \% v 16.6 \% ; \mathrm{p}=0.00034)$. The knee was most commonly affected in nonIVDAs (eight $v$ four cases), but this difference was not significant when compared with the IVDAs.

The bacteria responsible for the osteoarticular infections in the non-IVDAs were $S$ aureus (67\%)), $M$ tuberculosis (four (19\%)), $S$ pneumoniae (two (10\%)), and $B$ fragilis in one case $(5 \%)$. The only significant difference found between IVDAs and non-IVDAs was the prevalence of $C$ albicans (five $v 0 ; \mathrm{p}=0 \cdot 03$ ).

\section{Discussion}

INFLUENCE OF HIV IN DEVELOPING

OSTEOARTICULAR INFECTIONS

Since 1988 at least six large series have been published describing rheumatic diseases in HIV infected patients. ${ }^{3-57910}$ In those studies with a high proportion of homosexual men (75-92\% of HIV infected patients) a large number had seronegative spondylarthritis, mainly Reiter's syndrome, and no osteoarticular infections. ${ }^{3-5}$ In those studies with a high number of IVDAs (more than $80 \%$ ), however, fewer had spondylarthritis and osteoarticular infections predominated. ${ }^{7910}$ Hence the group at risk for HIV infection might influence the expression of HIV related rheumatic syndromes.

If the latter studies are excluded, osteoarticular infections in association with HIV infection are rarely reported. The first report published in 1985 described arthritis of small joints of the hand and wrist caused by Sporothrix schenckii. ${ }^{13}$ Since this report other infections in HIV positive patients caused by cryptococcus, ${ }^{14} S$ aureus, ${ }^{15-17}$ and $C$ albicans ${ }^{18}$ have been reported. Many of these occurred in association with disseminated infections. We published a preliminary description of articular mucormycosis included in this study. ${ }^{19}$

At least six cases of septic arthritis (one salmonella, two pneumococcus, and three $S$ aureus) occurred in six HIV positive haemo- philiac patients. ${ }^{20} 21$ Nonetheless, infectious arthritis can be a complication in HIV negative haemophiliac patients.

A recent publication ${ }^{22}$ reported 10 episodes of musculoskeletal infections in nine patients from a group of about $3000 \mathrm{HIV}$ positive patients $(0.3 \%)$. Of the nine patients, eight were homosexual and one was an IVDA. Five of them had septic arthritis, two had septic arthritis with osteomyelitis, one had osteomyelitis, one had musclar abscess, and one had bursitis. The infections were caused by $S$ aureus in four, Salmonella enteritidis in two, and pseudomonas, Histoplasma capsulatum, gonococcus, and $M$ kansai in one case each. Of the nine cases, seven had criteria for AIDS.

To our knowledge this is the first study in which the role of HIV in the development of osteoarticular infections has been examined. Our data showed no differences between HIV positive and HIV negative IVDAs for mean age, sex, affected joints, and causative agents. This suggests that HIV may not play a part in the development of osteoarticular infections. Possibly, the results were biased as the group of HIV negative patients was small. Thus further studies are needed.

Most of our HIV positive patients with osteoarticular infections were in CDC groups II and III, and only six of the $25(24 \%)$ were in group IV-Cl. Therefore profound immunological depression was present in only a few cases.

DIFFERENCES BETWEEN OSTEOARTICULAR INFECTIONS IN IVDAS AND NON-IVDAS About a half of IVDAs will develop an infectious complication, ${ }^{23}$ of which osteoarticular infections comprise $3 \cdot 2-4 \cdot 4 \% .^{23} 24$ From 1983 to 1988 the 'Spanish working group for the study of infections in drug addicts' registered 11645 infections, and septic arthritis or osteomyelitis was present in $291(2 \cdot 5 \%){ }^{25}$ Sacroiliac joints were most commonly affected $(23 \%)$, and $S$ aureus was the most commonly isolated agent (55\%).

Sacroiliac, sternocostal, and sternoclavicular joints are common sites of septic arthritis in IVDAs (table 3). ${ }^{26-29}$ These sites, however, are atypical in non-IVDAs, ${ }^{30}$ in whom the knee, shoulder, wrist, hip, interphalangeal, and elbow joints are the typical localities. ${ }^{31-34}$ As for IVDAs, $S$ aureus is the most common cause of infection in non-IVDAs, ${ }^{31-34}$ and candida is almost never present.

Although there are some differences between osteoarticular infections in IVDAs and nonIVDAs, we found no studies in which these differences were specifically examined. Our paper confirms that in IVDAs a significantly greater number of infections of axial jointsnamely, hip, sacroiliac, and sternocostal joints-are present than in non-IVDAs. In addition, $C$ albicans is found significantly more often in IVDAs than in non-IVDAs.

All the non-IVDAs studied were hospital inpatients and, furthermore, almost all (76\%) had a predisposing factor for joint infection. Thus the incidence of osteoarticular infections 
Table 3 Clinical features of the main reports about septic arthritis in drug addicts

\begin{tabular}{|c|c|c|c|c|c|c|c|c|c|c|}
\hline \multirow[t]{2}{*}{ Reference } & \multicolumn{6}{|c|}{ Affected joints } & \multicolumn{4}{|l|}{ Causative } \\
\hline & Sacroiliac & Sternocostal & Sternoclavicular & Knee & Hip & Other & $S$ aureus & $\begin{array}{l}\text { Psudomona } \\
\text { aeruginosa }\end{array}$ & Streptococcus & Other \\
\hline $\begin{array}{l}\text { Roca }^{26} \\
\text { Chandrasekar }^{27} \\
\text { López-Longo }^{28} \\
\text { Brancós } \\
\text { Present study }\end{array}$ & $\begin{array}{r}2 \\
3 \\
16 \\
16 \\
7\end{array}$ & $\begin{array}{r}0 \\
0 \\
15 \\
2 \\
5\end{array}$ & $\begin{array}{l}5 \\
3 \\
2 \\
8 \\
0\end{array}$ & $\begin{array}{r}3 \\
15 \\
3 \\
3 \\
4\end{array}$ & $\begin{array}{l}0 \\
3 \\
0 \\
5 \\
8\end{array}$ & $\begin{array}{r}2 \\
13 \\
5 \\
10 \\
7\end{array}$ & $\begin{array}{r}3 \\
24 \\
27 \\
27 \\
17\end{array}$ & $\begin{array}{l}8 \\
5 \\
0 \\
4 \\
0\end{array}$ & $\begin{array}{r}2 \\
11 \\
1 \\
1 \\
3\end{array}$ & $\begin{array}{l}1 \\
1 \\
9 \\
4 \\
2\end{array}$ \\
\hline
\end{tabular}

$(3 \cdot 4 \%)$ in this group cannot be extrapolated to the general population.

Intravenous drug abuse, itself, can be considered a risk factor for articular infections. Ang-Fonte et al attribute a fourfold increase of septic arthritis to this factor. ${ }^{35}$ In his paper $75 \%$ of 28 patients with non-gonococcal arthritis evaluated during 1981 and 1982 were IVDAs. This is a very high percentage when compared with the incidence of $35 \%$ reported in the same hospital during 1966-77.

The causative agents responsible for osteoarticular infections are similar to those found by others in Spain. ${ }^{28} 29$ In comparison with available American data, we and other Spanish authors found a lower number of Gram negative bacteria and methicillin resistant $S$ aureus. This suggests that geographical variations in the epidemiology of such infections may occur. It should be emphasised that the incidence of articular tuberculosis was not increased in IVDAs.

Several factors may account for the high incidence of infections in IVDAs: (a) HIV infection might be an important factor, but our data suggest that in osteoarticular infections this virus plays little part; (b) $S$ aureus, the most common cause of infection, has not been found in heroin samples, but IVDAs are often carriers of $S$ aureus $^{36}$; (c) unsterile drugs are injected with dirty needles and syringes; (d) dental hygiene is often poor; (e) bacterial clearance by the tracheobronchial system can be decreased during intoxication; $(f)$ promiscuity and prostitution increase the risk of transmitting infective agents; and, finally, $(g)$ cell mediated immunity may be impaired in IVDAs not only by HIV infection but also by intravenous drugs themselves. ${ }^{37}$

It is known that infectious agents each reach the synovial space through the bloodsteam. ${ }^{31}$ Why do IVDAs have a greater number of infections in the axial joints? Perhaps, the site of injection may play a part. ${ }^{27}$ This hypothesis, however, does not completely explain the increase of infections of sacroiliac, hip, and other axial joints in IVDAs. The high incidence of sternocostal infections is explained by disseminated candidiasis, which was present in $20 \%$ of our IVDAs. We found five cases of sternocostal infection and all were caused by this agent. The high incidence of $C$ albicans in IVDAs seems to be due to the use of brown heroin mixed with contaminated lemon. ${ }^{38} 39$ Therefore, the presence of disseminated candidiasis does not imply immune suppression related to AIDS. Systemic candidiasis has an initial phase with a septicaemic febrile syndrome that lasts between one and three days and a second phase characterised by the appearance of metastatic lesions, such as cutaneous (folliculitis, nodules, etc), ocular, and articular disease. The time between the acute phase and the articular disease ranges from 15 days to five months, ${ }^{38}$ and sternocostal infection is the most common and characteristic joint disease. ${ }^{39}$ The reason for this is unknown.

In conclusion, after searching for the influence of HIV infection in developing osteoarticular infections in IVDAs, we found that HIV seems to play little part. Intravenous drug abusers are younger and have a greater number of axial joint infections and have more arthritis due to candida than non-IVDAs. The epidemiology of the infections in our patients, similar to that reported by others in Spain, shows less Gram negative bacterial infections and methicillin resistant $S$ aureus than in the United States.

We thank Dr Dra J Uson for her careful revision of the English version of the manuscript. This work is supported by a grant from the 'Caja de Madrid' foundation.

1 Johnson T M, Duvic M, Rapini R P. AIDS exacerbates psoriasis. N Engl f Med 1985; 313: 1415

2 Winchester $R$ Bernstein D H, Fischer $H ~ D$, Enlow $R$, Solomon $\mathrm{G}$. The co-occurrence of Reiter's syndrome and acquired immunodeficiency. Ann Intern Med 1987; 106: 19-26.

3 Berman A, Espinoza L R, Díaz J D, et al. Rheumatic manifestations of human immunodeficiency virus infection. Am F Med 1988; 85: 59-64.

4 Buskila D, Gladman D D, Langevitz P, Bookman A A M, Fanning M, Salit I E. Rheumatologic manifestations of infection with the human immunodeficiency virus (HIV). Clin Exp Rheumatol 1990; 8: 567-73.

5 Calabrese L H, Kelley D M, Myers A, O'Connell M, Easley K. Rheumatic symptoms and human immunodeficiency virus infection. The influence of clinical and laboratory variables in a longitudinal cohort study. Arthritis Rheum 1991; 34: 257-63.

6 Muñoz-Fernández S, Cardenal A, Peña J M, et al. Manifestaciones reumatológicas e infección por VIH. Análisis de 284 pacientes VIH (+) [Abstract]. Rev Esp Análisis de 284 pacientes VIH
Reumatol 1990; 17 (suppl 1): 21 .

7 Muñoz-Fernández S, Cardenal A, Balsa A, et al. Rheumatic manifestations of 556 patients with the human immunodeficiency virus infection. Semin Arthritis Rheum 1991; 21: 30-9.

8 Muñoz-Fernández $\mathrm{S}$, Quiralte $\mathrm{J}$, Del Arco $\mathrm{A}$, et al. Osteoarticular infection associated with human immunodeficiency virus infection. Clin Exp Rheumatol 1991; 9: 489-93.

9 Monteagudo I, Rivera J, López-Longo J, Cosin J, Garcia-Monforte A, Carreño L. AIDS and rheumatic manifestations in patients addicted to drugs. An analysis manifestations in patients addicted to drugs.
of 106 cases. $\mathcal{F}$ Rheumatol $1991 ; 18: 1038-41$.

10 González J J, Aramburu J M, Gorozdo M, Santamaría J M. Manifestaciones reumáticas y/o sistémicas en pacientes Manifestaciones reumáticas y/o sistémicas en pacientes (Madrid) 1990; 7 (suppl 1): 116-7.

11 Centers for Disease Control. Revision of the CDC Centers for Disease Control. Revision of the CDC
surveillance case definition for acquired immunodeficiency syndrome. $\mathfrak{F} A M A$ 1987; 258: 1143-54.

12 Centers for Disease Control. Classification system for human T-lymphotropic virus type III/lymphadenopathyassociated virus infection. Ann Intern Med 1986; 105: 234-7.

13 Lipstein-Kresch E, Isenberg H D, Singer C, Cooke $Q$ Greenwald R A. Disseminated Sporothrix schencki infection with arthritis in a patient with the acquired immunodeficiency syndrome. $f$ Rheumatol 1985; 12 805-8. 
14 Ricciardici D D, Sepkowitz D V, Berkowitz L R, Bienenstock $\mathrm{H}$, Maslow M. Cryptococcal arthritis in a patient with acquired immune deficiency syndrome. Case report and review of the literature. $\mathcal{F}$ Rheumatol 1986; 13: report 8 .

15 Buskila D, Tenembaum J. Septic bursitis in human immunodeficiency virus infection. 7 Rheumatol 1989; 16: $1374-6$.

16 Goh B T, Jawad A S M, Chapman D, Winceslaus S J, Forster G E, Perry J D. Osteomyelitis presenting as a swollen elbow in a patient with the acquired immunedeficiency syndrome. Ann Rheum Dis 1988; 47: 695-6.

17 Zimmermann B, Erickson A D, Mikolich D J. Septic acromioclavicular arthritis and osteomyelitis in a patien with acquired immunodeficiency syndrome. Arthritis Rheum 1989; 32: 1175-6.

18 Edelstein H, McCabe R. Candida albicans septic arthritis and osteomyelitis of the sternoclavicular joint in a patient with human immunodeficiency virus infection. patient with human immun

19 Mostaza J M, Barbado F J, Fernández-Martín J, Mostaza J M, Barbado F J, Fernández-Martín J,
Peña-Yañez J, Vázquez-Rodriguez J J. Cutaneoarticular Peña-Yañez J, Vázquez-Rodriguez J J. Cutaneoarticular
mucormycosis due to Cunninghamella bertholletiae in a mucormycosis due to Cunninghamella bertholletia

20 Ragni M W, Hanley E N. Septic arthritis in hemophilic patients and infection with human immunodeficiency virus (HIV). Ann Intern Med 1989; 110: 168-9.

21 Bleasel J F, York J R, Rickard K A. Septic arthritis in human immunodeficiency virus infected haemophiliacs. $B r \mathcal{F}$ Rheumatol 1990; 29: 494-5.

22 Hughes R A, Rowe I F, Shanson D, Keat C S. Septic bone, joint and muscle lesions associated with human immunodeficiency virus infection. $B r f$ Rheumatol 1992; 31: 381-8.

23 Scheidegger C, Zimmerli W. Infectious complications in drug addicts: seven year review of 269 hospitalized narcotics abusers in Switzerland. Rev Infect Dis 1989; 11: narcotics

24 Crane L R, Levine D P, Zervos M J, Cummings G. Bacteriemia in narcotic addicts at the Detroit Medical Center. I. Microbiology, epidemiology, risk factors, and empiric therapy. Rev Infect Dis 1986; 8: 364-73.

25 Grupo de trabajo para el estudio de infecciones en drogacictos. Estudio multicéntrico de las complicaciones infecciosas en adictos a drogas por via parenteral en España: análisis de 11.645 casos (1977-88). Enfermedades Infecciosus y Microbiologia Clinica 1990; 8: 514-9.
26 Roca R P, Yoshikawa T T. Primary skeletal infections in heroin users: a clinical characterization, diagnosis and therapy. Clin Orthop 1979; 144: 238-48.

27 Chandrasekar P, Narula A P. Bone and joint infections in intravenous drug abusers. Rev Infect Dis 1986; 8: intravenous 11 .

28 López-Longo F, Menard H A, Carreño L, Cosín J Ballesteros R, Monteagudo I. Primary septic arthritis in heroin users: early diagnosis by radioisotopic imaging and heroin users: early diagnosis by radioisotopic imaging and geographic variation

29 Brancós M A, Peris P, Miró J M, et al. Septic arthritis in heroin addicts. Semin Arthritis Rheum 1991; 21: 81-7.

30 Vyskocil J J, Mcllroy M A, Brennan T A, Wilson F M Pyogenic infection of the sacroiliac joint. Case reports and review of the literature. Medicine (Baltimore) 1991; 70 188-97.

31 Goldenberg D I, Reed J I. Bacterial arthritis. N Engl f Med 1985; 312: 764-71.

32 Goldenberg D I, Cohen A S. Acute infectious arthritis. A review of patients with nongonococcal joint infections (with emphasis on therapy and prognosis). Am $\mathcal{F}$ Med 1976; 60: 369-77.

33 Newman J H. Review of septic arthritis throughout the antibiotic era. Ann Rheum Dis 1976; 35: 198-205.

34 Cooper C, Cawley M I D. Bacterial arthritis in an English health district: a 10 year review. Ann Rheum Dis 1986; 45: 458-63.

35 Ang-Fonte G Z, Rozboril M B, Thompson G R. Changes in nongonococcal septic arthritis: drug abuse and methicillin-resistant Staphylococcus aureus. Arthritis Rheum 1985; 28: 210-3.

36 Miró J M, Puig J, Gatell J M, et al. Estudio de la tasa de portadores cutaneomucosos de estafilococos en heroinómanos de área de Barcelona y de las características microbiológicas de la heroina y material de inyección. Med Clin (Barc) 1984; 83: 620-3.

37 Layon J, Idris A, Warzynski $M$, et al. Altered T-lymphocyte subsets in hospitalized intravenous drug abusers. Arch subsets in hospitalized intraven

38 Dupont B, Drouhet E. Cutaneous, ocular, and ocular osteoarticular candidiasis in heroin addicts: new clinical and therapeutic aspects in 38 patients. F Infect Dis 1985; 152: $577-91$

39 Miró J M, Brancós A, Abelló R, et al. Costochondral involvement in systemic candidiasis in heroin addicts: clinical, scintigraphic, and histologic features in 26 patients. Arthritis Rheum 1988; 31: 793-7. 